\title{
BMJ Open Assessment of patient centredness through patient-reported experience measures (ASPIRED): protocol of a mixed-methods study
}

Eva Christalle, Stefan Zeh, Pola Hahlweg, Levente Kriston, Martin Härter, Isabelle Scholl

To cite: Christalle E, Zeh S, Hahlweg P, et al. Assessment of patient centredness through patient-reported experience measures (ASPIRED): protocol of a mixedmethods study. BMJ Open 2018;8:e025896. doi:10.1136/ bmjopen-2018-025896

- Prepublication history for this paper is available online. To view these files, please visit the journal online (http://dx.doi org/10.1136/bmjopen-2018025896).

EC and SZ contributed equally.

Received 7 August 2018 Revised 1 September 2018 Accepted 12 September 2018

Check for updates

(C) Author(s) (or their employer(s)) 2018. Re-use permitted under CC BY-NC. No commercial re-use. See rights and permissions. Published by BMJ.

Department of Medical Psychology, University Medical Center Hamburg-Eppendorf, Hamburg, Germany

Correspondence to

Dr Isabelle Scholl;

i.scholl@uke.de

\section{ABSTRACT}

Introduction The impact of patient centredness (PC) in healthcare has grown over the years. However, conceptualisations of $\mathrm{PC}$ are heterogeneous. Existing patient-reported measures of $\mathrm{PC}$ have shown inconsistencies and shortcomings. This impedes the comparison of results across studies. To foster PC, it is important to know which dimensions matter most to patients and to be able to measure its current extent from the patients' perspective. This study aims (1) to assess relevance of dimensions of PC from the patients' perspective, (2) to develop and psychometrically test a core set of patient-reported experience measures (PREMs) assessing $\mathrm{PC}$ and (3) to investigate the feasibility of implementation of this core set in routine healthcare. Methods and analysis A mixed-methods approach will be used. In phase 1, 200 patients will assess the relevance of the dimensions of $\mathrm{PC}$ in a Delphi study using a plain language description. In phase 2, the core set of PREMs will be developed through literature reviews, focus groups, key informant interviews and content validity ratings. The core set will be tested psychometrically in a crosssectional study with 2000 inpatient and outpatients with different chronic conditions (ie, cancer, cardiovascular diseases, mental disorders and musculoskeletal disorders). In phase 3 , the feasibility of implementation of the core set will be assessed through semistructured interviews with healthcare practitioners after piloting in routine care. Furthermore, an expert workshop will be held on how to foster implementation.

Ethics and dissemination The study will be carried out in accordance to the latest version of the Helsinki Declaration of the World Medical Association and principles of good scientific practice. The study was approved by the Ethics Committee of the Medical Association Hamburg, Germany (study ID: PV5724). The study results will be disseminated in scientific journals and through collaboration partners and plain language press releases.

\section{INTRODUCTION}

The concept of patient centredness (PC) has been widely discussed over the last years. Research has shown that PC is positively associated with patient satisfaction, well-being

\section{Strengths and limitations of this study}

- No exhaustive patient-reported measure of patient centredness (PC) in Germany yet.

- Combination of quantitative and qualitative methods to ensure a comprehensive understanding of patients' perspectives.

- Dual purpose: development of a patient-reported measure of $\mathrm{PC}$ and investigation of the feasibility of its implementation.

- Extensive inclusion of patients' perspectives throughout development and evaluation of the measure.

- Limitation to four disease groups and geographical restriction to the metropolitan area of Hamburg, Germany.

and self-management, ${ }^{1-3}$ which are especially relevant in chronic disease management. Furthermore, the US Institute of Medicine declared patient-centred care to be one of six goals to achieve high-quality healthcare in their landmark publication 'Crossing the Quality Chasm' at the beginning of the 21st century. ${ }^{45}$ In Germany, specific federal funding programmes were initiated in order to foster research on high-quality care. ${ }^{6}$ Since 2013, the Patient Rights Law in Germany also stresses the importance of PC by outlining the right to informed decisions, comprehensive and comprehensible patient information and decisions based on the partnership of the patient and the clinician. ${ }^{7}$ Similar developments have been reported in the UK, Canada, Australia and several other countries. ${ }^{8}$

Unfortunately, a lack of conceptual clarity and inconsistencies in the use of the term complicate investigating and implementing PC. Several conceptual models have been developed, ${ }^{9-13}$ making it difficult to compare research results. Scholl and colleagues aimed to close this gap by developing an integrative 


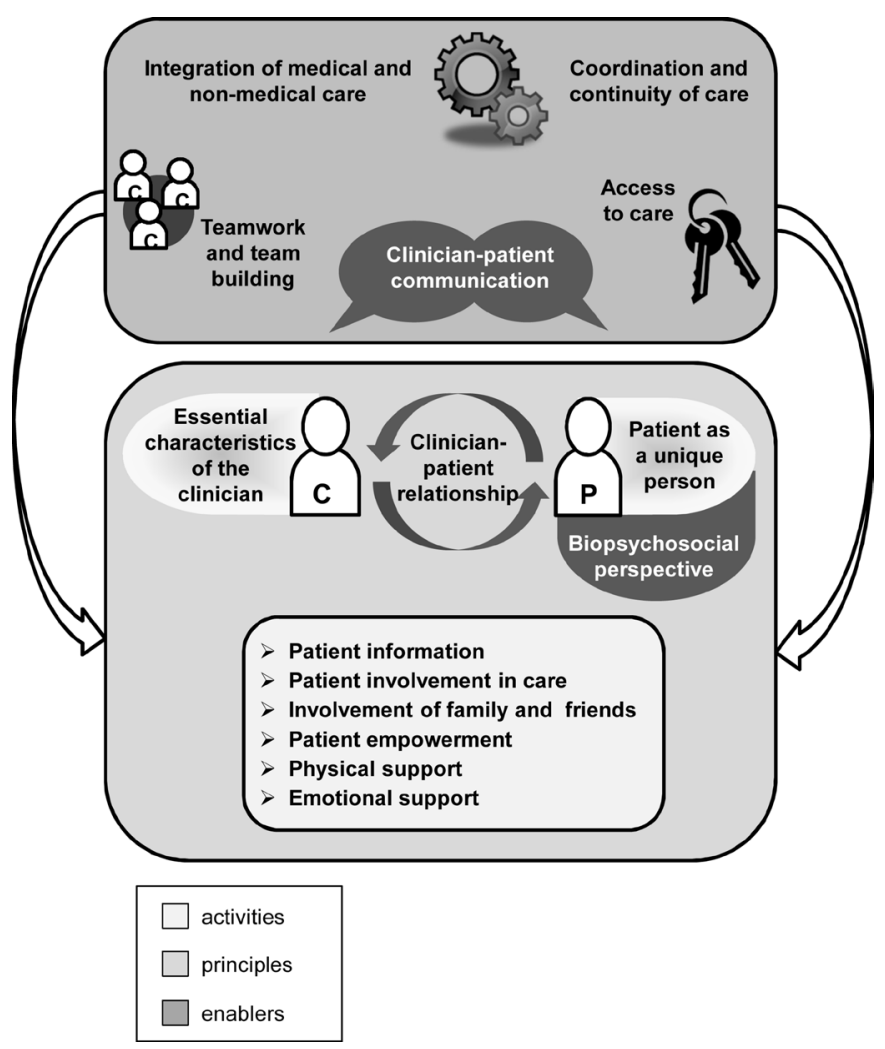

Figure 1 Integrative model of patient centredness.

generic model highlighting 15 dimensions of PC (see figure 1). ${ }^{14}$ In our research, we use this definition of PC. The model is based on a systematic review and was validated by assessing the relevance in a Delphi study conducted with $\mathrm{n}=71$ international experts. ${ }^{15}$ However, in this expert survey, patients' perspectives on clarity and relevance of the dimensions were not represented. ${ }^{15} \mathrm{~A}$ stronger focus on the patients' perspective on PC has been called for internationally. ${ }^{1617}$ If we want to change healthcare towards being more patient-centred, it is crucial to know which dimensions matter most to patients. ${ }^{1617}$ In order to foster and implement PC in routine practice, it is necessary to assess how patients actually experience the extent of realised PC. ${ }^{17-19}$

Patient-reported experience measures (PREMs) assess patients' experiences with processes in healthcare and could be a useful way forward regarding the measurement of PC. Contrary to patient-reported outcome measures (PROMs), PREMs did not yet receive considerable attention, ${ }^{20} 21$ especially in Germany. The measurement of satisfaction, which is a frequently used PROM, has traditionally produced ceiling effects. PREMs on the other hand aim to collect more information on whether specific aspects of healthcare delivery took place or not making them therefore more objective. ${ }^{22}$ Psychometrically sound PREMs are especially important for $\mathrm{PC}$, as patients are often the best or only source to assess to which extent healthcare is patient-centred. ${ }^{23}$ Similar to PROMs, standardised and validated PREMs can be used in multiple ways: as performance, benchmarking or quality improvement measures in health systems or healthcare provider organisations, in clinical trials, as well as in routine clinical practice for informing patients and clinicians. ${ }^{2425}$ Many countries and institutions have highlighted the importance of assessing patients' experiences. For example, in the UK, Scandinavian countries and the USA, patients' experiences are used to guide reimbursement of hospitals. ${ }^{26-29}$ Despite the large amount of international literature on measurement of PC, available measures display substantial variation due to disparity of underlying conceptualisations of PC. ${ }^{9} 30$ Furthermore, systematic reviews on the measurement of different dimensions of PC have revealed flaws in existing measures and a lack of psychometrically sound measures in German language. ${ }^{31-35}$ For example, measures were too long or psychometrically insufficient for valid comparisons and for a precise description of PC. ${ }^{31-35}$ Thus, it is important to develop and psychometrically test a core set of PREMs applicable to the German healthcare context. This will allow assessing the degree of PC of current German healthcare for the first time. Additionally, those results could be used internationally enriching the status quo of research of PC from the patients' perspective.

\section{Objectives}

This study aims (1) to assess content and relevance as well as the current implementation of dimensions of PC from the patients' perspective, (2) to develop and psychometrically test a core set of PREMs assessing PC and (3) to investigate the feasibility of implementation of the developed core set of PREMs in routine healthcare.

\section{METHODS AND ANALYSIS \\ Study population}

PC has been described as especially important in the large and heterogeneous population of patients with chronic conditions. ${ }^{36} 37$ The study will therefore focus on the perspectives of patients with chronic conditions from four disease groups: cancer, cardiovascular diseases, mental disorders and musculoskeletal disorders. Adult patients with conditions from the respective disease groups who have experienced treatment (outpatient and/or inpatient) in the past will be included. Patients with severe cognitive impairment and without sufficient command of the German language will be excluded. No other inclusion or exclusion criteria will be applied.

\section{Study design and data analyses}

This 5-year mixed-methods study comprises three phases. Each phase examines one of the objectives described above. Figure 2 gives an overview.

Phase 1: assessment of patients' views on dimensions of PC This phase aims at identifying which dimensions of PC are relevant to patients.

\section{Methods, procedures and instruments}

As a preparation for the relevance assessment, the first step will be to translate the integrative model of $\mathrm{PC}^{14}$ 


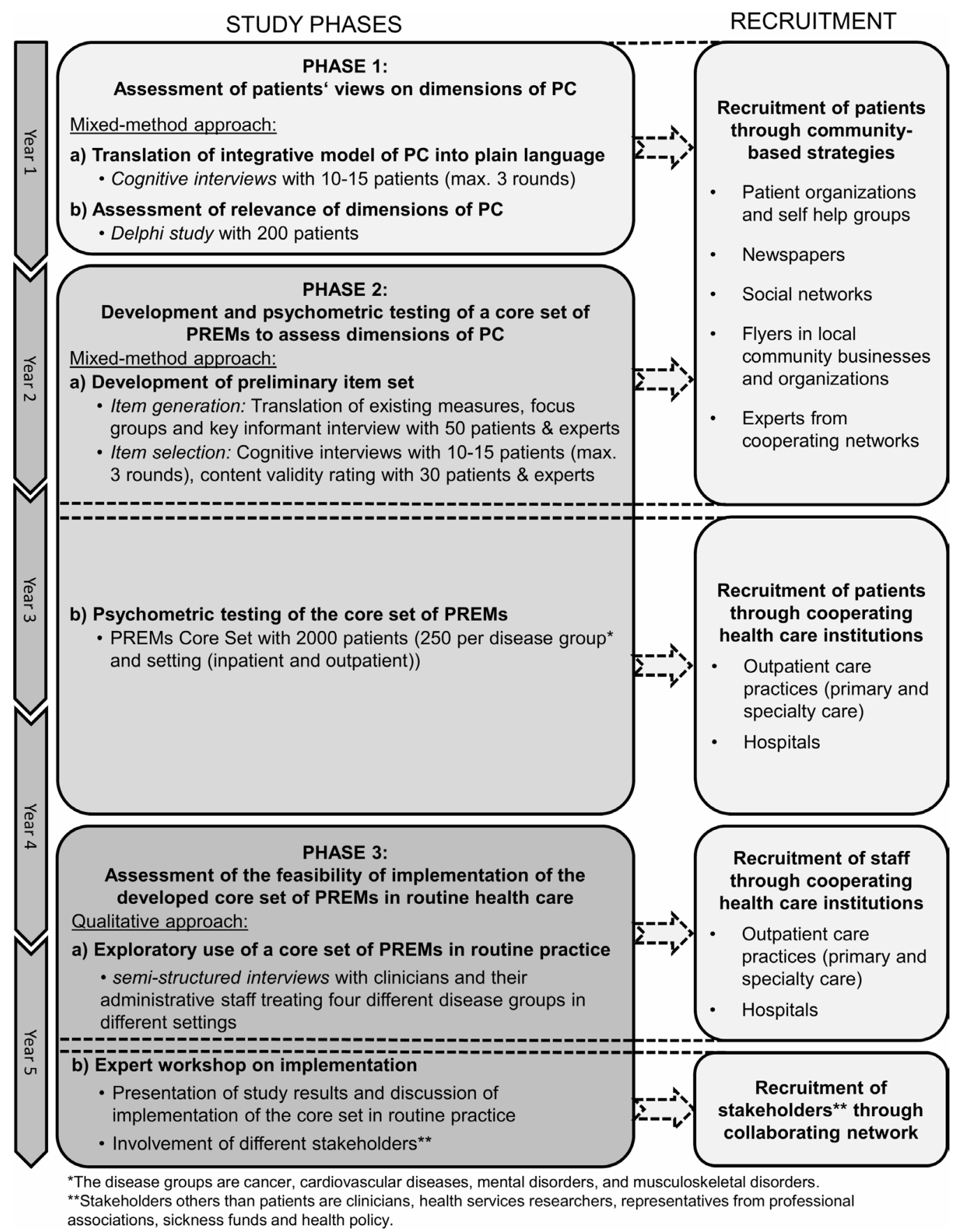

Figure 2 Overview of study design and patient recruitment strategies. PC, patient centredness; PREMs, patient-reported experience measures.

into a plain language version to make it more easily comprehensible for patients. Two researchers will independently translate the integrative model of PC into a plain language version. Next, they will generate a consensus version through discussion with two other members of the research team. Then, we will use cognitive interviewing with patients to test comprehensibility of the plain language model. Participants will be asked to read the plain language model step by step and to paraphrase in their own words what they have read. The cognitive interviews will be audio-recorded, transcribed and analysed independently by two researchers regarding misunderstandings as well as expressed difficulties with the text and suggestions for improvement. Based on the results, the plain language version will be revised in a group discussion between three researchers. Depending on the extent of revision necessary, a further round of cognitive interviews might be conducted, with a maximum of three rounds.

To assess the patient-reported relevance of the different dimensions of PC, a Delphi study will be conducted. Relevance in this case means the subjective importance of the different dimensions from the patients' view. In addition, we will assess to what extent those different 
aspects are already implemented in the German healthcare system according to the patients' subjective view. In a first round, participating patients will receive the revised plain language model as well as a questionnaire to rate the relevance and implementation of each dimension. In a second round, they will receive the median ratings of all participants as well as their own ratings from the first round. They will again be asked to rate the relevance and implementation. This procedure makes it possible to foster exchange and consensus within a large group of patients. The anonymity of the Delphi method helps to give all opinions an equivalent weight without dominance of certain persons, as might be the case in the personal contact within focus groups. ${ }^{38} 39$

For all patient participants, we will collect demographic data (eg, age, gender) with a short questionnaire. Furthermore, participants of the cognitive interviews will be asked to answer the European Health Literacy Questionnaire HLS-EU-Q16. This questionnaire was developed and used in The European Health Literacy Project (HLS-EU) in eight different European countries. ${ }^{40}{ }^{41}$ The German version was tested with $n=4952$ respondents. It showed an internal consistency of Cronbach's $\alpha=0.9$. The questionnaire is used, because health literacy might influence the ability to comprehend the plain language version. Thus, we want to make sure that we included some patients with a low health literacy as well.

\section{Recruitment/sample size}

Patients for phase 1 will be recruited through a range of community-based strategies (including media campaigns using newspaper announcements and flyers, as well as recruitment through patient organisations throughout Germany). This approach was chosen, as it has been shown to be less resource intensive than recruitment through healthcare institutions. ${ }^{42-44}$

For each round of cognitive interviews, approximately 10 to 15 participants are expected to be necessary to reach theoretical saturation. ${ }^{45} 46$

For the Delphi study, we aim to collect data from a total sample of 200 participants. This allows for calculating descriptive parameters with high precision for the total sample and warrants a sufficient precision of estimates for disease subgroups as well. To reach 200 participants in the second round, more participants need to be included in the first round. Former Delphi studies showed dropout rates from round 1 to round 2 ranging from $10 \%$ to $30 \% .{ }^{1547-49}$ We expect a rather small dropout rate of approximately $15 \%$, as patients will be reminded personally, and patients who participate in both rounds will receive a financial compensation. We therefore aim to recruit 236 patients for the first round.

\section{Data analysis}

We will analyse all sociodemographic data, health literacy scores and ratings from the Delphi survey descriptively (eg, frequencies, means, SD) for all participants as well as for subgroups according to the diseases of the participants.

Phase 2: development and psychometric testing of a core set of PREMs to assess dimensions of PC

Phase 2 aims to develop a core set of PREMs and test its psychometric properties. We will describe both steps separately in the following paragraphs.

\section{Phase 2a: Development of preliminary item set} Methods, procedures and instruments

Based on the relevance ratings of phase 1 , items for the core set of PREMs will be developed using multiple sources. First, we will conduct a literature search to identify existing international PREMs on PC. This search will include an electronic search as well as scanning of existing reviews on measures that assess dimensions of PC. ${ }^{32} 3455$ We will translate suitable items into German using a team translation process. This process consists of the following steps: (1) translation from original language to German by two independent translators, (2) suggestion of consensus version by third person and (3) final consensus team discussion. Furthermore, we will conduct focus groups and key informant interviews with patients as well as with experts (eg, clinicians, health services researchers, representatives from professional associations, sickness funds and health policies). Participants will be asked to generate items, which are suitable to measure PC based on the model from phase 1 .

All generated items will be tested using cognitive interviews with patients and revised if necessary to ensure that all items are comprehensible for the target population. Again, in this step, we will use the HLS-EU-Q16 to check the variance of health literacy within our sample.

In a second step, the number of items will be reduced if necessary. Experts and patients will be asked to rate the relevance of all generated items for measuring PC. In addition, they will be asked whether any important questions are missing. This allows to establish content validity by ensuring that all items are relevant as well as that they are reflecting PC comprehensively. ${ }^{51}$ Items rated as not relevant or less relevant will be dropped.

\section{Recruitment/sample size}

We plan to include 50 participants (patients and experts) in the focus groups and key informant interviews for item generation. For cognitive interviewing, we will recruit between 10 and 15 patients per round, with a maximum of three rounds. Content validity will be assessed by 5 to 10 experts as well as 5 to 10 patients, which corresponds to common recommendations. ${ }^{465253}$

Again, we will recruit patients via community-based strategies in the Hamburg area. Experts other than patients will be invited from our network of collaborating project partners and from the large regional Network for Healthcare Research Hamburg (HAM-NET; http:/ / hamnet.de/en/). 


\section{Data analysis}

The key informant interviews and focus groups will be recorded, transcribed and analysed via qualitative content analysis. ${ }^{54}$ Two researchers will conduct the analyses. Regular meetings with a third researcher will be held to ensure that coding schemes and analyses are comparable.

For content validity rating, a four-point Likert scale (1=not relevant, 2 =somewhat relevant, $3=$ quite relevant and $4=$ very relevant) will be used. ${ }^{465} 53$ We will examine frequencies and median of the content validity ratings. Furthermore, we will calculate the Content Validity Index ${ }^{465253}$ to explore inter-rater agreement of the relevance ratings for each item.

\section{Phase 2b: psychometric testing}

Methods, procedures and instruments

After the development of the preliminary item set, its psychometric characteristics will be tested. Patients will be asked to fill in a survey. The survey will include the developed items as well as selected validated measures that test related constructs to establish construct validity. For example, we will use the first item of the German version of 12-Item Short Form Survey ${ }^{55}$ to explore discriminant validity. This item explores the general perception of health status and is expected to show a low correlation $<0.3 .^{27}$ For convergent validity, we will for example assess satisfaction with the treatment by using the German version of the 8-item Client Satisfaction Questionnaire (ZUF-8).$^{56}$ For satisfaction, we expect a high correlation $>0.5 .^{27}$

The decision whether further measures will be used to test construct validity will be part of the preparation for phase $2 \mathrm{~b}$ and can only be determined once the content of the item set emerges from the data. The core set of PREMS will be revised according to the results of phase 2b. We will delete items according to common thresholds in floor and ceiling effects, intraclass correlations or Kappa and loadings in factor analysis (eg, items with more than $20 \%$ of the replies at one end of the scale and items with intraclass correlations or Kappa coefficients below $0.40^{57}$ ).

\section{Recruitment/sample size}

Patients will be recruited in healthcare institutions in the metropolitan area of Hamburg, Germany (eg, academic cancer centre, academic heart centre, psychosomatic clinic, primary care practices). Consecutive sampling will be used in participating outpatient and inpatient healthcare institutions of primary and secondary care. This way, only patients that are currently being treated in a specific healthcare institution will be included in this study phase.

To examine the factorial structure of items and to perform analyses of associations among variables with sufficient precision and power, an approximate sample size of 250 participants per group will be targeted. Overall, there will be eight groups as we collect data from each of the four disease groups in two settings (inpatient and outpatient). Therefore, we aim for a total sample size of 2000 participants. This allows for the use of maximum likelihood or weighted least squared estimators in the investigation of moderately complex models and for the detection of weak but meaningful correlations $(r=0.20)$ with an alpha error probability of $\alpha=0.05$ and a power of 0.90 . The exact methods of assessment, statistical analyses and exact necessary sample sizes will be determined once phase $2 \mathrm{a}$ is completed, and the exact number of items and measures of the core set has been decided on.

\section{Data analysis}

We will calculate several psychometric indices. We will examine internal consistency using Cronbach's $\alpha$ or the Kuder Richardson 20 coefficient (depending on the response format of items). For further item reduction and assessment of structural validity, we will analyse item characteristics (discrimination and difficulty) and perform exploratory factor analysis. To assess construct validity, we will calculate correlations. We will use t-tests and Mann-Whitney U-tests (depending on the distribution of the outcome) to assess discriminant validity. We will examine floor and ceiling effects using descriptive analyses by comparing the distribution of the observed values to the theoretically possible range of values. As a proxy of acceptability, we will examine if there are systematic patterns of missing data or low response rates. ${ }^{58} \mathrm{We}$ do not examine retest reliability and inter-rater reliability, as we do not expect the measured construct to remain stable over time or between people.

Phase 3: assessment of the feasibility of implementation of the developed core set of PREMs in routine healthcare

In phase 3 , we aim to investigate the feasibility of implementation of the developed core set of PREMs in routine healthcare in a phase of exploratory use.

\section{Methods, procedures and instruments}

Collaborating healthcare organisations will be offered to use the final core set of PREMs in their routine practice. As a first step, onsite meetings with staff of participating healthcare institutions will be held. Those have the purpose to come to a shared understanding on how to best administer the core set of PREMs within the current clinical workflow of the respective institution. In these meetings, we will, for example, discuss who should give the core set to the patients, at what time point exactly and how the replies should be collected. In addition, the participating institutions will be able to decide whether they want to receive the results of the PREMs core set in order to use them as performance feedback. These onsite meetings will be followed by a phase of exploratory use of several weeks. After this phase of exploratory use, we will conduct interviews. Specifically, we will ask the participating staff how they organised the implementation and whether they made adaptions to better fit the setting requirement. Furthermore, we will ask which barriers and facilitators they experienced and which steps need to be 
taken in order to further use the PREMs core set in their routine care.

As a second step of phase 3 , we will conduct an expert workshop on implementation of the core set of PREMS in routine care. This workshop aims at (1) presenting the results of the psychometric testing and the assessment of PC in routine practice, and (2) discussing opportunities for the implementation of the core set in routine practice after testing it in the phase of exploratory use. This discussion aims to bring together the results from the semistructured interviews in the pilot phase as well as the knowledge and experience of the participating experts. It will cover both the implementation at individual healthcare organisations as well as the implementation as a potential quality indicator for purposes of accountability and quality improvement at the health system level. ${ }^{25}$

\section{Recruitment/sample size}

For the pilot test, we aim to interview 10 to 15 clinicians and administrative staff from our collaborating healthcare organisations where the core set of PREMs was tested.

We plan to conduct the workshop with 25 to 30 experts. This will allow inviting a range of experts with different backgrounds and areas of expertise (eg, clinicians, health services researchers, representatives from professional associations, sickness funds and health policy). At the same time, it is a sample size feasible to allow the realisation of discussions in small groups and in the full group. They will be invited from our network of collaborating project partners and HAM-NET.

\section{Data analysis}

The interviews and focus groups will be recorded, transcribed and analysed via qualitative content analysis. ${ }^{54}$ The analyses will be conducted by two researchers. Regular meetings with a third researcher will be held to ensure that coding schemes and analyses are comparable.

\section{Patient and public involvement}

Patients were not involved in the development of the research questions. However, during the development of the research proposal and prior to submission to the funding agency, we obtained collaboration agreements with several federal and regional patient organisations in order to secure field access and feasibility. Patient organisations were approached for that purpose. All gave us positive feedback on the study aims, acknowledging that more research is needed on patients' experiences related to patient-centred care. Thus, patient organisations will support recruitment of study participants by disseminating advertisement for study participation. No individual patient will be involved in recruitment and conduct of the study. All study participants and every interested person in the public will have the possibility to read and download regular project updates and study results on the project website (http://www.ham-net.de/ de/projekte/projekt-aspired.html).

\section{Software}

We will use the software IBM SPSS Statistics (IBM Corp., Armonk, New York, USA) for most quantitative data analyses. Additionally, we will perform structural equation modelling with Mplus (Muthén \& Muthén, Los Angeles). To support the transcription of focus groups and interviews, we will use the software F4 transkript (dr. dresing \& pehl $\mathrm{GmbH}$, Marburg). We will use the software MAXQDA (VERBI GmbH, Berlin) to support all qualitative data analyses.

\section{ETHICS AND DISSEMINATION \\ Ethical and safety considerations}

The study will be carried out according to the latest version of the Helsinki Declaration of the World Medical Association. Principles of good scientific practice will be respected. Study participation is voluntary and no foreseeable risks for participants result from the participation in this study. Participants will be fully informed about the aims of the study, data collection and the use of collected data. Written informed consent will be sought prior to participation. Preserving principles of data sensitivity, data protection and confidentiality requirements will be met.

\section{Dissemination plan}

During the course of the study, a biannual newsletter will be made available to study participants, collaboration partners and the interested public to inform them about the progress of the study and its results. This newsletter will be made available for download on the project website. The results of the project will be published in scientific journals. To ensure high accessibility, we aim to publish our work in open access journals, if feasible. Furthermore, dissemination of the project's results will also be part of the implementation workshop of phase 3 , which will include different stakeholders. Additionally, the results will be presented at relevant national and international conferences. Finally, the resulting core set of PREMs assessing PC will be made available for download free of charge under a Creative Commons License.

Acknowledgements We thank our student assistants Sophia Schulte and Tanja Kloster who supported us in preparing the manuscript. We are thankful for the support of many national and regional patient organisations: Bundesselbsthilfeverband für Osteoporose, Deutsche Fibromyalgie Vereinigung, Deutsche Gesellschaft für Prävention und Rehabilitation von Herz-Kreislauferkrankungen, Frauenselbsthilfe nach Krebs, Haus der KrebsSelbsthilfe, Kontakt- und Informationsstellen für Selbsthilfegruppen in Hamburg, Landesverband Psychiatrie-Erfahrener, Nationale Kontakt-und Informationsstelle zur Anregung und Unterstützung von Selbsthilfegruppen and Rheuma-Liga. Furthermore, we would like to thank our collaborating health care institutions: Landesverband Hamburg der Deutschen Gesellschaft für Psychosomatische Medizin und Ärztliche Psychotherapie, OptiMedis AG, RehaCentrum Hamburg/ Klinikum Bad Bramstedt, Schön Klinik Eilbek and the University Medical Center Hamburg-Eppendorf (Center for Health Care Research, Department of General Practice/Primary Care, Department of Psychiatry and Psychotherapy, Taskforce Patient-Centeredness, University Cancer Center and University Heart Center). Finally, we would like to thank further individuals for their collaboration and support: Paul Barr (Dartmouth College, USA), Debra de Silva (The Evidence Center), Marie-Luise Dierks (Hannover Medical School), Ed Harding (The Health Policy 
Partnership), David Klemperer (Ostbayerische Technische Hochschule Regensburg), Christoph Kranich (Consumer Association Hamburg), Jürgen Matzat (Kontaktstelle für Selbsthilfegruppen der Deutschen Arbeitsgemeinschaft Selbsthilfegruppen e.V.), Hardy Müller (Wissenschaftliches Institut der TK für Nutzen und Effizienz im Gesundheitswesen) and Edmund Neugebauer (University Witten/Herdecke).

Contributors EC and SZ contributed to the specification of the study design and wrote the first draft of the manuscript in equal shares. IS, PH, LK and MH conceptualised and designed the study, wrote the grant proposal and obtained funding. They also critically revised the manuscript for important intellectual content. IS is the responsible primary investigator of the project. All authors gave final approval of the version to be published and agree to be accountable for the work

Funding This work is funded by the German Federal Ministry of Education and Research (Bundesministerium für Bildung und Forschung-BMBF) with grant number $01 \mathrm{GY} 1614$.

Disclaimer The funder reviewed and approved the study design during the grant application process, but had no role in decision to publish or preparation of the manuscript.

Competing interests None declared.

Patient consent Not required.

Ethics approval Ethics Committee of the Medical Association Hamburg, Germany (study ID: PV5724).

Provenance and peer review Not commissioned; peer reviewed for ethical and funding approval prior to submission.

Open access This is an open access article distributed in accordance with the Creative Commons Attribution Non Commercial (CC BY-NC 4.0) license, which permits others to distribute, remix, adapt, build upon this work non-commercially, and license their derivative works on different terms, provided the original work is properly cited, appropriate credit is given, any changes made indicated, and the use is non-commercial. See: http://creativecommons.org/licenses/by-nc/4.0/.

\section{REFERENCES}

1. Rathert C, Wyrwich MD, Boren SA. Patient-centered care and outcomes: a systematic review of the literature. Med Care Res Rev 2013;70:351-79.

2. Robinson JH, Callister LC, Berry JA, et al. Patient-centered care and adherence: definitions and applications to improve outcomes. J Am Acad Nurse Pract 2008;20:600-7.

3. Castro EM, Van Regenmortel T, Vanhaecht K, et al. Patient empowerment, patient participation and patient-centeredness in hospital care: a concept analysis based on a literature review. Patient Educ Couns 2016;99:1923-39.

4. Berwick DM. A user's manual for the iom's 'quality chasm' report Health Aff 2002;21:80-90.

5. Leavitt M. Medscape's response to the institute of medicine report: Crossing the quality chasm: A new health system for the 21st century. MedGenMed 2001;3:233-5.

6. Härter M, Dirmaier J, Scholl I, et al. The long way of implementing patient-centered care and shared decision making in Germany. Z Evid Fortbild Qual Gesundhwes 2017;123-124:46-51.

7. Bundestag. Gesetz zur Verbesserung der Rechte von Patientinnen und Patienten: Bundesgesetzblatt, 2013:277-82. 2013. https:// www.bgbl.de/xaver/bgbl/start.xav?startbk=Bundesanzeiger_BGBI\& start=//.

8. Härter M, Moumjid N, Cornuz J, et al. Shared decision making in 2017: International accomplishments in policy, research and implementation. Z Evid Fortbild Qual Gesundhwes 2017;123124:1-5.

9. Epstein RM, Franks P, Fiscella K, et al. Measuring patient-centered communication in patient-physician consultations: theoretical and practical issues. Soc Sci Med 2005;61:1516-28.

10. Mead N, Bower P. Patient-centredness: a conceptual framework and review of the empirical literature. Soc Sci Med 2000;51:1087-110.

11. Ouwens M, Hermens R, Hulscher M, et al. Development of indicators for patient-centred cancer care. Support Care Cancer 2010;18:121-30.

12. Stewart MA, Brown JB, Weston W, et al. Patient-centered medicine transforming the clinical method. Abingdon: Radcliffe Medical Press, 2003.

13. van Dulmen S. Patient-centredness. Patient Educ Couns 2003;51:195-6.
14. Scholl I, Zill JM, Härter M, et al. An integrative model of patientcenteredness - a systematic review and concept analysis. PLoS One 2014;9:e107828.

15. Zill JM, Scholl I, Härter M, et al. Which dimensions of patientcenteredness matter? - Results of a web-based expert delphi survey. PLoS One 2015;10:e0141978.

16. Bensing J, Rimondini M, Visser A. What patients want. Patient Educ Couns 2013;90:287-90.

17. Hudon C, Fortin M, Haggerty J, et al. Patient-centered care in chronic disease management: a thematic analysis of the literature in family medicine. Patient Educ Couns 2012;88:170-6.

18. Luxford K. What does the patient know about quality? Int J Qual Health Care 2012;24:439-40.

19. Härter M, Müller H, Dirmaier J, et al. Patient participation and shared decision making in Germany - history, agents and current transfer to practice. Z Evid Fortbild Qual Gesundhwes 2011;105:263-70.

20. Black N. Patient reported outcome measures could help transform healthcare. BMJ 2013;346:f167-7.

21. Rolfson O, Rothwell A, Sedrakyan A, et al. Use of patient-reported outcomes in the context of different levels of data. $J$ Bone Joint Surg Am 2011;93:66-71.

22. Garratt AM, Bjaertnes $\varnothing A$, Krogstad U, et al. The outpatient experiences questionnaire (opeq): Data quality, reliability, and validity in patients attending 52 norwegian hospitals. Qual Saf Health Care 2005;14:433-7.

23. Anhang Price R, Elliott MN, Zaslavsky AM, et al. Examining the role of patient experience surveys in measuring health care quality. Med Care Res Rev 2014;71:522-54.

24. Nelson EC, Eftimovska E, Lind C, et al. Patient reported outcome measures in practice. BMJ 2015;350:g7818.

25. Patwardhan $A$, Spencer $\mathrm{CH}$. Are patient surveys valuable as a service-improvement tool in health services? An overview. J Healthc Leadersh 2012;4:33-46.

26. Department of Health. The NHS Outcomes Framework 2011 / 12 Framework, 2010:56.

27. Oltedal S, Garratt A, Bjertnaes $\varnothing$, et al. The NORPEQ patient experiences questionnaire: data quality, internal consistency and validity following a Norwegian inpatient survey. Scand J Public Health 2007:35:540-7.

28. Giordano LA, Elliott MN, Goldstein E, et al. Development, implementation, and public reporting of the HCAHPS survey. Med Care Res Rev 2010;67:27-37.

29. Szablowski KM. Hospital Value-Based Purchasing (VBP) program: measurement of quality and enforcement of quality improvement. Conn Med 2014;78:49-51.

30. McCormack LA, Treiman K, Rupert D, et al. Measuring patientcentered communication in cancer care: a literature review and the development of a systematic approach. Soc Sci Med 2011:72:1085-95.

31. Barr PJ, Scholl I, Bravo P, et al. Assessment of patient empowerment--a systematic review of measures. PLoS One 2015;10:e0126553

32. Müller E, Zill JM, Dirmaier J, et al. Assessment of trust in physician: a systematic review of measures. PLoS One 2014;9:e106844.

33. Scholl I, Frerichs W, Christalle E, et al. Assessment of patient information needs: a systematic review of measures. PLoS One 2015;10:e0126553

34. Scholl I, Koelewijn-van Loon M, Sepucha K, et al. Measurement of shared decision making - a review of instruments. Z Evid Fortbild Qual Gesundhwes 2011;105:313-24.

35. Zill JM, Christalle E, Müller E, et al. Measurement of physician-patient communication-a systematic review. PLoS One 2014;9:e112637.

36. Holman H, Lorig K. Patients as partners in managing chronic disease. Partnership is a prerequisite for effective and efficient health care. BMJ 2000;320:526-7.

37. McMillan SS, Kendall E, Sav A, et al. Patient-centered approaches to health care: a systematic review of randomized controlled trials. Med Care Res Rev 2013;70:567-96.

38. Häder M. Delphi-Befragungen: Ein Arbeitsbuch: Springer VS, 2014

39. Boulkedid R, Abdoul H, Loustau M, et al. Using and reporting the Delphi method for selecting healthcare quality indicators: a systematic review. PLoS One 2011;6:e20476.

40. Pelikan J, Ganahl K. Die europäische Gesundheitskompetenz-Studie: Konzept, Instrument und ausgewählte Ergebnisse. 2017.

41. Jordan S, Hoebel J. Gesundheitskompetenz von erwachsenen in deutschland. Bundesgesundheitsblatt Gesundheitsforschung Gesundheitsschutz 2015;58:942-50.

42. Brewster WR, Anton-Culver H, Ziogas A, et al. Recruitment strategies for cervical cancer prevention study. Gynecol Oncol 2002;85:250-4.

43. Brill SE, El-Emir E, Allinson JP, et al. Community-based recruitment of patients with COPD into clinical research. Thorax 2014;69:951-2. 
44. Davey R, Edwards SM, Cochrane T. Recruitment strategies for a clinical trial of community-based water therapy for osteoarthritis. $\mathrm{Br} \mathrm{J}$ Gen Pract 2003;53:315-7.

45. Beatty PC, Willis GB. Research synthesis: the practice of cognitive interviewing. Public Opin Q 2007;71:287-311.

46. Streiner DL, Norman GR, Cairney J. Health measurement scales: a practical guide to their development and use. 2015

47. Greatorex J, Dexter T. An accessible analytical approach for investigating what happens between the rounds of a Delphi study. $J$ Adv Nurs 2000;32:1016-24.

48. Rognstad S, Brekke M, Fetveit A, et al. The Norwegian General Practice (NORGEP) criteria for assessing potentially inappropriate prescriptions to elderly patients. A modified Delphi study. Scand J Prim Health Care 2009;27:153-9.

49. Nowack M, Endrikat J, Guenther E. Review of delphi-based scenario studies: quality and design considerations. Technol Forecast Soc Change 2011;78:1603-15.

50. De Silva D, 2014. Helping measure person-centred care: a review of evidence about commonly used approaches and tools used to help measure person-centred care www.health.org.uk/helpingmeasurepcc (accessed 12 Feb 2018).

51. Mokkink LB, Terwee CB, Patrick DL, et al. The COSMIN checklist for assessing the methodological quality of studies on measurement properties of health status measurement instruments: an international Delphi study. Qual Life Res 2010;19:539-49

52. Polit DF, Beck CT. The content validity index: are you sure you know what's being reported? Critique and recommendations. Res Nurs Health 2006;29:489-97.

53. Lynn MR. Determination and quantification of content validity. Nurs Res 1986;35:382-5.

54. Schreier M. Varianten qualitativer Inhaltsanalyse: ein wegweiser im dickicht der Begrifflichkeiten. Forum Qual Sozialforsch 2014;15.

55. Wirtz MA, Morfeld M, Glaesmer H, et al. Konfirmatorische Prüfung der Skalenstruktur des SF-12 Version 2.0 in einer deutschen bevölkerungs-repräsentativen Stichprobe. Diagnostica 2018;64:84-96

56. Kriz D, Nübling R, Steffanowski $A$, et al. Patientenzufriedenheit in der stationären Rehabilitation: psychometrische reanalyse des zuf-8 auf der basis multizentrischer stichproben verschiedener indikation. Zeitschrift für Medizinische Psychol 2008;17:67-79.

57. Andresen EM. Criteria for assessing the tools of disability outcomes research. Arch Phys Med Rehabil 2000;81:S15-S20.

58. Sepucha KR, Matlock DD, Wills CE, et al. "It's Valid and Reliable" Is Not Enough: critical appraisal of reporting of measures in trials evaluating patient decision aids. Med Decis Making 2014;34:560-6. 